\title{
The correlation research on yak meat texture profile analysis (Tpa) and freshness parameters during refrigerated storage
}

\begin{abstract}
The possible relationships of yak meat using PLSR between freshness and TPA parameters during cold storage were studied. Texture profile analysis (TPA) and freshness measurements of yak meat under the $4^{\circ} \mathrm{C}$ stored $0 \mathrm{~d}, 2 \mathrm{~d}, 4 \mathrm{~d}, 6 \mathrm{~d}, 8 \mathrm{~d}, 10 \mathrm{~d}$ and $12 \mathrm{~d}$ were also performed. In addition, partial least squares regression analysis was carried out to find a correlation between the freshness data and TPA parameters. Significant $(p<0.05)$ correlations among the freshness data and adhesiveness, cohesiveness, Springiness, chewiness and resilience were observed, Multivariate Regression analysis indicated that predictive regression equations of every parameters with all equations Fitting coefficient R2 greater than 0.800 . Validation test R2 greater than 0.900 , which showed a clear correlation between yak meat chemical changes and its texture properties during refrigeration. The results in this study could be used to explore the Texture profile analysis (TPA) important for using the TPA parameters rapidly evaluates yak meat freshness.
\end{abstract}

Volume I Issue 4 - 2015

\author{
Gaoliang Bao,' Li Zhang, ${ }^{1,2}$ Baozhong Sun, ${ }^{2}$ \\ Peng Xie, ${ }^{2}$ Li Wang,' Jun Niu,' Jibing Ma' \\ 'College of Food Science and Engineering, Gansu Agriculture \\ University, China \\ ${ }^{2}$ Institute of Animal Science, Chinese Academy of Agricultural \\ Sciences, China
}

\begin{abstract}
Correspondence: Li Zhang, College of Food Science and Engineering, Gansu Agriculture University, Lanzhou, Gansu,
\end{abstract} China, Tel 1366935275I, Email 2418558449@qq.com

Received: October 22, 2015 | Published: November 25, 2015

Keywords: freshness, yak meat, correlation, textural properties

Abbreviations: TPA, texture profile analysis; TVB-N, total volatile basic nitrogen; TBA, thiobarbituric acid; POV, peroxide value; TMA-N, trimethylamine nitrogen; MDA, malondialdehyde

\section{Introduction}

Yak (Bos grunniens) is the large ruminant species in the high altitude Qinghai-Tibetan Plateau, China, which is characterized by year-round low temperatures and hypoxic atmosphere. There is the most yaks in China, and yak meat is an natural green food. ${ }^{1}$ The protein content of yak meat is about $22 \%$, fat content is lower than $3 \%,{ }^{2}$ it's a kind of high protein, low fat animal foods. A chemical change of yak meat by the endogenous enzymes and the pathogenic microorganisms, and also the sensory properties and the composition changed, nutritional value reduce, and there are some toxic or harmful substances the same time, it's harmful to the consumers, ${ }^{3}$ it is a comprehensive evaluation index that freshness of yak meat could be used as a judgment during cold storage, it is largely reflects the meat quality, nutritional value and safety coefficient. ${ }^{4}$ So measuring the freshness of yak meat during cold storage, which can effectively prevent food health security problem occurs, how to accurately and objective measure of yak meat freshness using rapid methods, it's a subject of intense interest in recent years.

At present, the methods of evaluation the yak meat freshness is mainly measuring the freshness parameters (TVB-N value, TBA value, POV value, TMA-N value). ${ }^{5}$ Proteins come into being the alkaline nitrogenous substances due to microorganism and endogenous enzymes during storage, One of the most main is volatile base nitrogen, TVB-N value is one of the important indicators to evaluate meat freshness, it is can be evaluate the meat freshness by measuring the value of TVB-N, and it is used as a national standard of measuring meat freshness. ${ }^{6}$ Fat occur different degree oxidation in the during storage, and TBA value show lipid secondary oxidation products or the number of the final products. ${ }^{7}$ However, there is a disadvantages that needs complicated sample preparation work and trival test operation, complex Procedure, consuming too much time. It is not convenient to frequently and widely implement, it cannot satisfy far from rapid and large quantities measurement, ${ }^{8}$ it is a urgent request that find a method of rapid measurement. In recent years, many scholars have studied the relationship between sensory evaluation and instrumental determination values. It is observed that three is a significant or extremely significant correlation between the textural properties and the sensory evaluation value of pork. ${ }^{9}$ The correlations between the textural properties and volume water content of date palm..$^{10}$ It was observed that hardness and springiness decreased linearly with the increase of water content, whereas increased linearly with the increase of fat content. ${ }^{11}$

Despite the above investigations, there is no study reported yet about the determination of textural properties parameters for evaluation of yak meat freshness using PLSR. Therefore, in this study, we prepared yak meat emulsion samples and kept at $4{ }^{\circ} \mathrm{C}$ stored $0 \mathrm{~d}$, $2 \mathrm{~d}, 4 \mathrm{~d}, 6 \mathrm{~d}, 8 \mathrm{~d}, 10 \mathrm{~d}$ and $12 \mathrm{~d}$, the freshness and Texture profile analysis (TPA) measurements were also performed. The aim of this study was to analyze possible relationship the correlation of yak meat using PLSR between freshness and TPA parameters of yak meat. ${ }^{10}$

\section{Materials and methods}

\section{Description of the samples}

Seven samples $(1.0 \mathrm{~kg}$ for each sample, clear plastic wraps packaged) of Yak meats were obtained from amdo group. The 7 samples were kept at $4^{\circ} \mathrm{C}$ stored $0 \mathrm{~d}, 2 \mathrm{~d}, 4 \mathrm{~d}, 6 \mathrm{~d}, 8 \mathrm{~d}, 10 \mathrm{~d}$ and $12 \mathrm{~d}$. All the Yak meats were subjected to each type of chemical and textural analysis.

\section{Chemicals}

All reagents used were of analytical-reagent grade, PE composite 
packaging film was purchased from Tian Hua Xin Yu plastic products co., LTD, picric acid was obtained from Xin Ding Peng Fei development of science and technology co., LTD, methylbenzene, formaldehyde, trichloroacetic acid, magnesium oxide, boric acid, mixture indicator, hydrochloric acid, TBA, Potassium carbonate, anhydrous sodium sulfate, Saturated potassium iodide, starch indicator, $\mathrm{Na}_{2} \mathrm{~S}_{2} \mathrm{O}_{3}$, trichloromethane were obtained from The recovery of Fine Chemical Industry Research Institute, and these reagents used were of analytical-reagent grade.

\section{Apparatus}

A Thermostat oscillator (Shanghai, China) was used to heat preservation, Spectrophotometric measurements were carried out using a spectrophotometer, employing a quartz cuvette with a $1.0 \mathrm{~cm}$ optical path, the TPA measurements were carried out using a TA. XT Express texture analyzer.

\section{Experimental design}

The study selected gannan amdo group yak meat as the research object and the average divided into seven groups packaged by $\mathrm{PE}$ composite packaging film, refrigeration $0 \mathrm{~d}, 2 \mathrm{~d}, 4 \mathrm{~d}, 6 \mathrm{~d}, 8 \mathrm{~d}, 10 \mathrm{~d}$ and $12 \mathrm{~d}$ Under the condition of $0 \sim 4^{\circ} \mathrm{C}$ low temperature, freshness and textural properties measurement of yak meat were performed.

Determination of TVB-N: Using semi-micro distillation method, TVB-N value was determined by a stream distillation method with some modifications. ${ }^{12}$ Ten grams of long is simus dorsi muscle of yak was minced and then mixed with $100 \mathrm{~mL}$ water, filtered after immersion $30 \mathrm{~min}$. The distillate was collected in a conical flask containing $50 \mathrm{~mL}$ aqueous solution of boric acid $(40 \mathrm{~g} / \mathrm{L})$ and a mixed indicator created from dissolution of $0.1 \mathrm{~g}$ of methyl red and $0.1 \mathrm{~g}$ of bromocresol green into $100 \mathrm{~mL}$ of $95 \%$ ethanol. $5.0 \mathrm{~mL}$ of the filtrate in distiller reaction chamber, and 5.0mL Magnesium oxide mixed suspension $(10 \mathrm{~g} / \mathrm{L})$ and distilled for $10 \mathrm{~min}$ in a $8100 \mathrm{Kjeltec}$ Distillation Unit, Afterward, the obtained boric acid solution was titrated with a $0.01 \mathrm{M}$ of hydrochloric acid solution. The violet colors was the titration end point, At the same time do a blank test. And each analysis was repeated in triplicate.

The TVB-N value was measured and expressed as mg N/100g yak meat muscle according to the consumption of hydrochloric acid. The TVB-N value was calculated by the following formula.

$$
X=\frac{\left(V_{1}-V_{2}\right) \times c \times 14}{m \times \frac{5}{100}} \times 100
$$

Where $\mathrm{X}$ is the content of TVB-N value of meat sample (mg/100g), $V_{l}$ is the volume of the hydrochloric acid standard solution for the titration $(\mathrm{mL})$ of sample, $V$ is the volume of the hydrochloric acid standard solution for the titration $(\mathrm{mL})$ of blank, $\mathrm{c}$ is the concentration of hydrochloric acid solution, $(\mathrm{mol} / \mathrm{L}), \mathrm{m}$ is the quality of the meat sample (g).

Criterion: The content of TVB-N value less than $15 \mathrm{mg} / 100 \mathrm{~g}$ was Fresh meat, between 15 and $25 \mathrm{mg} / 100 \mathrm{~g}$ was Second level, more than $25 \mathrm{mg} / 100 \mathrm{~g}$ was metamorphic corruption meat.

TBA analysis: TBARS content was determined colorimetrically by the method of Pokorny et al., ${ }^{13}$ Samples $(2.0 \mathrm{~g})$ were homogenized in $10 \mathrm{ml}$ of $7.5 \%$ Trichloroacetic acid solution (including $0.1 \% \mathrm{EDTA}$ ), centrifuged $\square 1600 \mathrm{r} / \mathrm{min} \square 5 \mathrm{~min}, 5.0 \mathrm{~mL}$ of the filtrate heat preservation $40 \mathrm{~min}$ in $90^{\circ} \mathrm{C}$ Water bath pot with $5.0 \mathrm{~mL} \mathrm{TBA}(0.02 \mathrm{~mol} / \mathrm{L})$, and absorbance measurement in $532 \mathrm{~nm}$ and $600 \mathrm{~nm}$ wavelength

The TBA value was calculated by the following formula:

$$
T B A(m g / k g)=13.51 \times\left(A_{532}-A_{600}\right)-0.061
$$

Where $\mathrm{A}_{532}$ is $532 \mathrm{~nm}$ wavelength absorbance values; $\mathrm{A}_{600}$ is $600 \mathrm{~nm}$ wavelength absorbance values.

Peroxide value (POV): The Peroxide value was determined according to Jung's methods. ${ }^{14} 2.0 \mathrm{~g}$ of meat sample was dissolved in $20 \mathrm{~mL}$ of chloroform and acetic acid (2:3) solution with $1.00 \mathrm{~mL}$ Potassium iodide saturated solution, $30 \mathrm{~mL}$ distilled water and $1.0 \mathrm{~mL}$ Starch indicator. The POV of Yak meat was analyzed by titration with $0.002 \mathrm{M} \mathrm{Na}_{2} \mathrm{~S}_{2} \mathrm{O}_{3}$ solution using an iodometry.

The POV was calculated using the equation:

$$
P=\frac{1000\left(V-V_{0}\right) c}{2 m}
$$

Where $V$ is the volume of the $0.002 \mathrm{M} \mathrm{Na}_{2} \mathrm{~S}_{2} \mathrm{O}_{3}$ solution for the titration $(\mathrm{mL})$ of sample, $V_{0}$ is the volume of the $0.002 \mathrm{M} \mathrm{Na}_{2} \mathrm{~S}_{2} \mathrm{O}_{3}$ solution for the titration $(\mathrm{mL})$ of blank, $\mathrm{c}$ is the concentration of the $0.002 \mathrm{M} \mathrm{Na}_{2} \mathrm{~S}_{2} \mathrm{O}_{3}$ factor and $\mathrm{m}$ is the weight of the sample $(\mathrm{g})$.

Procedure for TMA-N determination in yak meat samples: The Peroxide value was determined according to methods. Extraction of TMA-N from yak meat samples was performed according to Pena-Pereira's. ${ }^{15}$ procedure by homogenising $5.0 \mathrm{~g}$ of yak meat muscles with $17.5 \mathrm{~mL}$ and $2.5 \mathrm{~mL}$ of $40 \%$ (mass/volume) aqueous trichloroacetic acid (TCA) solution and subsequent centrifugation of the homogenate at $3000 \mathrm{rpm}$ for $15 \mathrm{~min}$. The supernatant liquid was placed in a volumetric flask and enough TCA at 7.5\% (mass/volume) concentration was added to make up to $25 \mathrm{ml}$. then $2 \mathrm{~mL}$ volume of the meat extract was placed into a $40 \mathrm{~mL}$-amber vial containing a stirring bar together with $5 \mathrm{~mL}$ of a salted $(30 \%$ mass/volume $\mathrm{NaCl})$ aqueous solution and $1 \mathrm{~mL}$ of formaldehyde( $39 \%$ mass/volume). Then $2 \mathrm{~mL}$ of $\mathrm{NaOH}(10 \mathrm{M})$ were injected trough the septum. $10 \mathrm{~mL}$ xylene drop containing $0.02 \%$ mass/volume of picric acid was then formed at the needle tip of a microsyringe and exposed to the headspace of the sample stirred at $1100 \mathrm{rpm}$ for $3.5 \mathrm{~min}$. The extractant solution must be refrigerated into a water-ice bath before extraction to extend the microextraction time and, therefore, enhance the extraction efficiency of TMAN. Finally, the remaining drop was retracted back into the microsyringe and placed on the pedestal of the Nanodrop spectrophotometer to obtain the corresponding analytical signal.

The TMA-N was calculated using the equation:

$$
T M A-N(m g / 100 g)=\frac{100 \times c \times V}{1000 \times V_{1} \times m}
$$

Where $V$ is the volume of the sample solution diluted $(\mathrm{mL}), V_{I}$ is the volume of the consumed sample solution $(\mathrm{mL})$, $\mathrm{c}$ is Equivalent to a standard liquid concentration $(\mathrm{mol} / \mathrm{L}), \mathrm{m}$ is the weight of the sample (g). 
TPA: In general, four cylinders $1.5 \mathrm{~cm}$ high and $2 \mathrm{~cm}$ wide were prepared from every sample. ${ }^{16}$ A double compression cycle test was performed up to $50 \%$ compression of the original portion height with an aluminium cylinder probe of $2 \mathrm{~cm}$ diameter. A time of $5 \mathrm{~s}$ was allowed to elapse between the two compression cycles. Force-time deformation curves were obtained with a $25 \mathrm{~kg}$ load cell applied at a cross-head speed of $2 \mathrm{~mm} / \mathrm{s}$. The following parameters were quantified. ${ }^{17}$ hardness $(\mathrm{N})$ maximum force required to compress the sample, springiness (m), ability of the sample to recover its original form after deforming force was removed, adhesiveness (Ns), area under the abscissa after the first compression, and cohesiveness, extent to which the sample could be deformed prior to rupture. ${ }^{18}$

\section{Statistical analyses}

Data were analysed of various index determination results mean and standard deviation using Excel 2010 software and Data were analysed statistically using SPSS20.0 software. Selection of each fresh ness $0 \mathrm{~d}, 2 \mathrm{~d}, 6 \mathrm{~d}, 8 \mathrm{~d}, 12 \mathrm{~d}$ experimental result doing regression analysis and $4 \mathrm{~d}, 10 \mathrm{~d}$ Validation test.

\section{Results and Discussion}

\section{Freshness}

The variance analysis of freshness determination results of yak meat in the process of refrigeration are shown in Table 1. The plots and regression of freshness of the yak meat during cold storage are shown in Figures 1-4. The regression equations of freshness of the yak meat during cold storage are shown in Table 2. Total volatile basic nitrogen (TVB-N) content is one of core indicators for evaluating meat freshness, ${ }^{19}$ Table 1 shows the TVB-N of yak meat during cold storage higher than the $28.16 \mathrm{mg} / 100 \mathrm{~g}$ on the sixth day and rotten, inedible, TVB-N for all yak meat increased throughout storage and up to a final value of to $31.76 \mathrm{mg} / 100 \mathrm{~g}$ on the twelfth day. This value is close to the determination results In the process of storage reported by Li Ting ting. ${ }^{20}$ TBARS has been used to determine the degree of lipid oxidation, and the presence of TBA reactive substances is due to the second stage of auto-oxidation, during which peroxides are oxidized to aldehydes and ketones. A TBA value of $2 \mathrm{mg} \mathrm{MDA} / \mathrm{kg}$ is the limit. The change in TBARS of yak meat during cold storage is $0.3 \mathrm{mg} \mathrm{MDA} / \mathrm{kg}$ and under $2 \mathrm{mg} \mathrm{MDA} / \mathrm{kg}$, the determination results in agreement with the reported by Fan. ${ }^{21}$ The POV provides the oxidation state of the lipids..$^{22}$ This value was used to measure the rancidity that occurred by auto-oxidation. The POV of meat extracted significant increased throughout storage, TMA-N value being of widespread use. Concentration of TMA-N in yak meat has been found to be closely related to organoleptic estimations, being an objective quality indicator for freshness determination in meat samples. ${ }^{23}$ TMA-N generation is attributed to the gradual conversion of trimethylamine oxide (TMA-O) by bacterial or enzymatic reduction. An increase on the level of TMA-N was observed from this initial value up to a final value of $1.08 \mathrm{mg} / 100 \mathrm{~g} \pm 0.042 \mathrm{mg}$ TMA-N/100g.

\section{TPA}

The variance analysis of textural properties determination results of yak meat in the process of refrigeration are shown in Table 3. Hardness is the power of Cut off meat about textural properties, which was the internal binding force to maintain the shape of the meat. ${ }^{24} \mathrm{An}$ increase on the level of Hardness was observed from this initial value up to 6 day value of $111.37 \pm 1.14 \mathrm{~g}$, after 6 day of storage, the Hardness was decline, Storage 12days later than 0 days was reduced by $47 \%$; Springiness was the meat deformation under the external force and the ability to restore the original state after the external force to remove..$^{25}$ The Springiness decreased continuously during cold storage and up to $0.66 \pm 0.12 \mathrm{~mm}$ on the $12 \mathrm{day}$. The cohesiveness is resistance to damage when chewing food, the properties of the intact of food, which show yak meat internal bond strength. ${ }^{26}$ Cohesiveness decreases during the whole storage, a decrease on the level of Cohesiveness was observed from this initial value up to a final value of $0.49 \pm 0.010$ on the 12 day, falling 39\% than on the 0day. Adhesiveness is the work of overcoming attractive power between yak meat surface and the contact surfaces, is the first extrusion negative peak area of Instrument definition, ${ }^{27}$ the adhesiveness increases in the storage, an Significant increase on the level of adhesiveness was observed from this initial value up to 12 day value of $171.92 \pm 1.45 \mathrm{~mJ}$. Chewiness is related to the hardness, springiness and cohesiveness, which is the power to chewing yak meat, it is equal to the product between the hardness and cohesiveness, ${ }^{28}$ in our study, the values of chewiness decrease in the storage. Resilience is restoration degree that the yak meat was pressured, ${ }^{29}$ the values of resilience decreases in the study and the final value Smaller than 0day.

\section{The correlation between freshness and TPA parameters}

The correlation between the freshness and TPA parameters of yak meat during cold storage are shown in Table 4. Freshness and TPA attributes of different dates are presented in Table 4 respectively. Initial statistical analysis showed that Hardness did not improve correlation with the freshness parameters $(p>0.05)$. Springiness, Cohesiveness, Chewiness, Resilience negatively correlated with freshness parameters $(\mathrm{p}<0.05)$ and Adhesiveness index positively correlated with freshness parameters $(p<0$. 01). Therefore, the traditional multiple linear regression unsuitable to this analysis, using the freshness as the dependent variable and values of hardness et al. six textural parameters as independent variables were implemented to establish the innovative models for prediction of freshness quality of yak meat based upon the PLSR using SPSS and the statistical results are in Table 5.

Partial least squares regression analysis is a method of multivariate data analysis based on principal component analysis and principal component regression, which is a dimension reduction techniques that dimension reduction space prediction the covariance matrix of each element and the prediction matrix to maximize. ${ }^{30}$ According to the standard of cumulative contribution to x more than $75 \%$, the Table 5 shows that the first potential factors can preferable explain the original independent variables, the values of cumulative contribution TVB-N value, TBA value, POV value, TAM-N value based on the developed PLSR models were $79.0 \%, 79.1 \%, 79.0 \%, 79.1 \%$, respectively which indicated the regression equation regression effect is very good. Meanwhile, the textural properties parameters was more powerful in predicting TVB-N values, TBA values, POV value, TMA-N value, which also demonstrated that PLSR was suitable and competent for selecting the informative variables in this study. Regression equations show in Table 5.

$\mathrm{Y}$ is the dependent variable shows in Table $6, \mathrm{x}_{1} \sim \mathrm{x}_{6}$ is the Springiness, hardness, cohesiveness, adhesiveness, chewiness, resilience respectively, the predicted value of the dependent variable can be obtained according to regression equation, the prediction results and the verification results of Each parameters shows in Figures 5-8. 
The decay and Metamorphism, protein degradation and fat oxidation of yak meat during cold storage due to the endogenous enzymes and microorganisms. which has a great influence on yak meat textural properties, ${ }^{31}$ freshness and texture profile analysis (TPA) measured, Partial least squares regression analysis was performed to determine the degree of association freshness versus textural properties, were implemented to establish the predicted models for prediction of freshness quality of yak meat based upon the PLSR and the statistical results are illustrated in Figure 5-8, PLSR was used to analyze correlations between the values of freshness data and TPA parameters of the model system yak meat emulsions.

Using the $0 \mathrm{~d}, 2 \mathrm{~d}, 6 \mathrm{~d}, 8 \mathrm{~d}, 12 \mathrm{~d}$ freshness measured results as the horizontal axis and predicted results as vertical axis obtained scatter diagrams, and $4 \mathrm{~d}, 10 \mathrm{dmeasured}$ results as verification test. From the Figures 5-8 can be seen, the values of $\mathrm{R}^{2}$ of TVB-N value, TBA value, POV value, TAM-N value based on the developed PLSR models were $0.924,0.801,0.882,0.906$, respectively. In addition, the average relative error between predicted values and measured values of TVB-N value, TBA value, POV value, TAM-N value were $0.1 \%$, $8.9 \%, 6.9 \%, 7.6 \%$, respectively. Meanwhile, it could be seen from the above study that the Predicted value similar to the measured value, and the values of $\mathrm{R} 2 \mathrm{v}$ were greater than 0.90 , the relative errors were less than 5\%. Therefore, the PLSR was more powerful in predicting TVB-N value, TBA value, POV value, TMA-N value with texture profile analysis (TPA) parameters, which also demonstrated that TPA could evaluate yak meat freshness during cold storage in this study.

Table I The variance analysis of freshness determination results of yak meat in the process of refrigeration

\begin{tabular}{lllll}
\hline Time $(\mathbf{d})$ & TVB-N $(\mathbf{m g} / \mathbf{1 0 0 g})$ & $\begin{array}{l}\text { TBA } \\
(\mathbf{m g ~ M D A} / \mathbf{k g})\end{array}$ & POV $(\mathbf{m m o l} / \mathbf{k g})$ & TMA-N $(\mathbf{m g} / \mathbf{1 0 0 g})$ \\
\hline 0 & $6.66 \pm 2.90^{\mathrm{a}}$ & $0.08 \pm 0.029^{\mathrm{a}}$ & $0.49 \pm 0.010^{\mathrm{a}}$ & $0.48 \pm 0.003^{\mathrm{a}}$ \\
\hline 2 & $14.90 \pm 1.50^{\mathrm{a}}$ & $0.13 \pm 0.010^{\mathrm{a}}$ & $0.67 \pm 0.017^{\mathrm{b}}$ & $0.51 \pm 0.012^{\mathrm{b}}$ \\
4 & $24.05 \pm 0.84^{\mathrm{a}}$ & $0.16 \pm 0.019^{\mathrm{a}}$ & $0.87 \pm 0.024^{\mathrm{c}}$ & $0.71 \pm 0.002^{\mathrm{c}}$ \\
6 & $28.16 \pm 0.65^{\mathrm{a}}$ & $0.20 \pm 0.019^{\mathrm{b}}$ & $0.98 \pm 0.021^{\mathrm{d}}$ & $0.85 \pm 0.007^{\mathrm{c}}$ \\
8 & $29.76 \pm 0.39^{\mathrm{b}}$ & $0.28 \pm 0.014^{\mathrm{b}}$ & $1.29 \pm 0.021^{\mathrm{e}}$ & $0.87 \pm 0.006^{\mathrm{d}}$ \\
10 & $30.83 \pm 1.00^{\mathrm{c}}$ & $0.26 \pm 0.009^{\mathrm{b}}$ & $1.53 \pm 0.031^{\mathrm{f}}$ & $0.96 \pm 0.011^{\mathrm{e}}$ \\
12 & $31.76 \pm 1.55^{\mathrm{d}}$ & $0.31 \pm 0.029^{\mathrm{c}}$ & $1.84 \pm 0.031^{\mathrm{g}}$ & $1.08 \pm 0.042^{\mathrm{e}}$ \\
$P$ values & 0.015 & 0.0032 & $1.2 \times 10^{-9}$ & $5.1 \times 10^{-11}$ \\
\hline
\end{tabular}

Different letters in the same column indicate significant differences $(p<0.05)$.

Table $\mathbf{2}$ The regression equation of freshness of the yak meat during cold storage

\begin{tabular}{lll}
\hline y values & Equation of linear regression & Fitting coefficients $\boldsymbol{R}^{2}$ \\
\hline TVB-N $(\mathrm{mg} / 100 \mathrm{~g})$ & $\mathrm{y}=2.0158 \mathrm{x}+11.637$ & $R^{2}=0.8421$ \\
$\mathrm{TBA}(\mathrm{mg} \mathrm{MDA} / \mathrm{kg})$ & $\mathrm{y}=0.0188 \mathrm{x}+0.0886$ & $R^{2}=0.9500$ \\
$\mathrm{POV}(\mathrm{mmol} / \mathrm{kg})$ & $\mathrm{y}=0.1102 \mathrm{x}+0.4336$ & $R^{2}=0.9821$ \\
TMA-N $(\mathrm{mg} / 100 \mathrm{~g})$ & $\mathrm{y}=0.0539 \mathrm{x}+0.4639$ & $R^{2}=0.9632$ \\
\hline
\end{tabular}

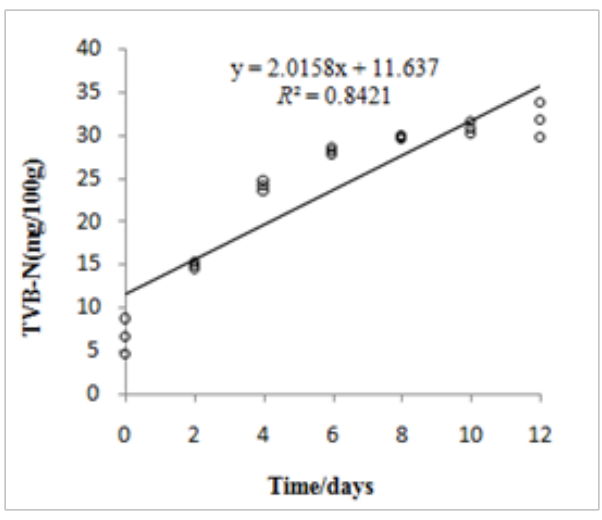

Figure I TVB-N value of yak meat during storage.

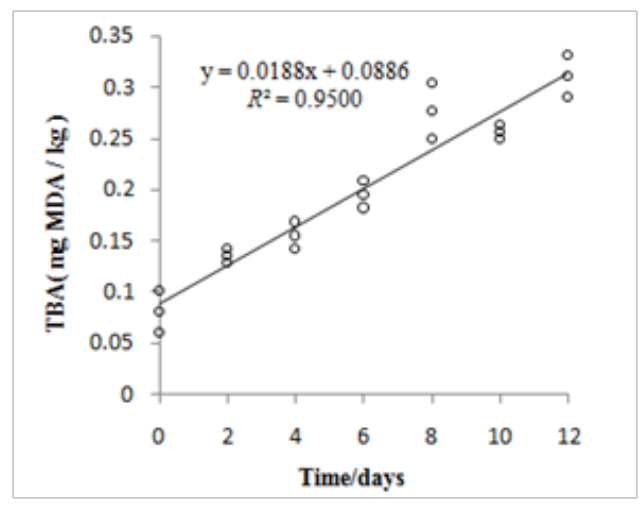

Figure 2 TBA value of yak meat during storage. 
Table 3 The variance analysis of textural properties determination results

\begin{tabular}{|c|c|c|c|c|c|c|}
\hline Time(d) & $\begin{array}{l}\text { Springiness } \\
(\mathrm{mm})\end{array}$ & Hardness(g) & Cohesiveness & $\begin{array}{l}\text { Adhesiveness } \\
(\mathrm{mJ})\end{array}$ & Chewiness (mJ) & Resilience \\
\hline 0 & $4.59 \pm 0.07^{\mathrm{a}}$ & $105.44 \pm 1.69^{\mathrm{ab}}$ & $0.81 \pm 0.003^{\mathrm{a}}$ & $61.50 \pm 3.07^{\mathrm{f}}$ & $368.28 \pm 11.84^{\mathrm{a}}$ & $0.45 \pm 0.012^{\mathrm{a}}$ \\
\hline 2 & $2.47 \pm 0.11^{\mathrm{b}}$ & $101.29 \pm 1.39^{\mathrm{b}}$ & $0.80 \pm 0.014^{\mathrm{a}}$ & $65.37 \pm 7.57^{\mathrm{f}}$ & $227.75 \pm 24.00^{\mathrm{b}}$ & $0.38 \pm 0.022^{\mathrm{b}}$ \\
\hline 4 & $1.75 \pm 0.17^{\mathrm{c}}$ & $102.78 \pm 2.37^{b}$ & $0.62 \pm 0.002^{\mathrm{b}}$ & $78.39 \pm 3.99^{\mathrm{e}}$ & $112.74 \pm 4.06^{\mathrm{d}}$ & $0.36 \pm 0.009^{d}$ \\
\hline 6 & $0.99 \pm 0.001^{\mathrm{d}}$ & $111.37 \pm 1.14^{\mathrm{a}}$ & $0.58 \pm 0.013^{\mathrm{c}}$ & $120.56 \pm 3.89^{\mathrm{d}}$ & $156.72 \pm 7.39^{\mathrm{c}}$ & $0.38 \pm 0.004^{b}$ \\
\hline 8 & $0.79 \pm 0.001^{\mathrm{e}}$ & $107.20 \pm 5.58^{\mathrm{ab}}$ & $0.61 \pm 0.006^{\mathrm{b}}$ & $143.26 \pm 2.35^{\mathrm{c}}$ & $114.61 \pm 5.20^{c}$ & $0.37 \pm 0.001^{\mathrm{bc}}$ \\
\hline 10 & $0.68 \pm 0.001^{\mathrm{e}}$ & $92.48 \pm 5.61^{\mathrm{c}}$ & $0.63 \pm 0.024^{\mathrm{b}}$ & $156.48 \pm 5.19^{b}$ & $82.93 \pm 3.99^{\mathrm{e}}$ & $0.35 \pm 0.003^{\mathrm{d}}$ \\
\hline 12 & $0.66 \pm 0.12^{\mathrm{e}}$ & $55.54 \pm 4.16^{\mathrm{d}}$ & $0.49 \pm 0.010^{\mathrm{d}}$ & $171.92 \pm 1.45^{\mathrm{a}}$ & $53.77 \pm 7.07^{\mathrm{f}}$ & $0.33 \pm 0.006^{\mathrm{e}}$ \\
\hline$P$ values & 0.0031 & 0.068 & 0.015 & $1.1 \times 10-8$ & $1.3 \times 10-11$ & 0.00065 \\
\hline
\end{tabular}

Different letters in the same column indicate significant differences $(p<0.05)$.

Table 4 Correlation coefficients $(r)$ between the freshness and TPA parameters

\begin{tabular}{|c|c|c|c|c|c|c|c|c|c|c|}
\hline Index & TVB-N & TBA & POV & TMA-N & Sp & На & Co & Ad & Ch & $\operatorname{Re}$ \\
\hline TVB-N & 1 & & & & & & & & & \\
\hline TBA & $0.878^{* *}$ & 1 & & & & & & & & \\
\hline POV & $0.854^{*}$ & $0.940^{* *}$ & 1 & & & & & & & \\
\hline TMA-N & $0.936^{* *}$ & $0.926^{* *}$ & $0.956^{* *}$ & 1 & & & & & & \\
\hline $\mathrm{Sp}$ & $-0.972^{* *}$ & $-0.856^{* *}$ & $-0.813^{* *}$ & $-0.888^{* *}$ & 1 & & & & & \\
\hline $\mathrm{Ha}$ & -0.36 & -0.476 & $-0.627^{*}$ & -0.487 & 0.325 & 1 & & & & \\
\hline Co & $-0.906^{* *}$ & $-0.814^{* *}$ & $-0.836^{* *}$ & $-0.931^{* * *}$ & $0.845^{* *}$ & 0.35 & 1 & & & \\
\hline Ad & $0.863^{* *}$ & $0.957^{* *}$ & $0.956^{* *}$ & $0.961^{* *}$ & $-0.814^{*}$ & -0.496 & $-0.826^{* *}$ & 1 & & \\
\hline $\mathrm{Ch}$ & $-0.940^{* *}$ & $-0.838^{* * *}$ & $-0.843^{*}$ & $-0.874^{* *}$ & $0.956^{* *}$ & 0.455 & $0.860^{* * *}$ & $-0.774^{* *}$ & 1 & \\
\hline $\mathrm{Re}$ & $-0.817^{* * *}$ & $-0.713^{* *}$ & $-0.751^{* *}$ & $-0.739^{* *}$ & $-0.871^{* * *}$ & 0.515 & $0.749^{* * *}$ & $-0.622^{*}$ & $0.949^{\text {*** }}$ & 1 \\
\hline
\end{tabular}

Sp, springiness; $\mathrm{Ha}$, hardness; Co, cohesiveness; Ad, adhesiveness; Ch, chewiness; Re, resilience

$* \mathrm{p}<0.05$, ** $\mathrm{p}<0.01$. 
Table 5 Proportion of variance explained

\begin{tabular}{|c|c|c|c|c|c|c|}
\hline$Y$ values & $\begin{array}{l}\text { Latent } \\
\text { factors }\end{array}$ & $\mathrm{X}$ variance & $\begin{array}{l}\text { Cumulative } X \\
\text { variance }\end{array}$ & $Y$ variance & $\begin{array}{l}\text { Cumulative } Y \text { variance } \\
\left(R^{2}\right)\end{array}$ & Adjusted $R^{2}$ \\
\hline \multirow{4}{*}{$\begin{array}{l}\text { TVB-N value } \\
\text { (mg/100g) }\end{array}$} & 1 & 0.79 & 0.79 & 0.937 & 0.937 & 0.924 \\
\hline & 2 & 0.122 & 0.911 & 0.06 & 0.996 & 0.994 \\
\hline & 3 & 0.058 & 0.969 & 0.003 & 0.999 & 0.998 \\
\hline & 4 & 0.017 & 0.987 & 0 & 0.999 & 0.998 \\
\hline \multirow{5}{*}{$\begin{array}{l}\text { TBA value } \\
(\mathrm{mg} \mathrm{MDA} / \mathrm{kg})\end{array}$} & 5 & 0.013 & 1 & 0 & 1 & 0.997 \\
\hline & 1 & 0.791 & 0.791 & 0.835 & 0.835 & 0.801 \\
\hline & 2 & 0.086 & 0.876 & 0.062 & 0.897 & 0.845 \\
\hline & 3 & 0.074 & 0.951 & 0.024 & 0.921 & 0.843 \\
\hline & 4 & 0.045 & 0.996 & 0.006 & 0.927 & 0.782 \\
\hline \multirow{5}{*}{$\begin{array}{l}\text { POV value } \\
(\mathrm{mmol} / \mathrm{kg})\end{array}$} & 5 & 0.004 & 1 & 0.011 & 0.939 & 0.631 \\
\hline & 1 & 0.79 & 0.79 & 0.902 & 0.902 & 0.882 \\
\hline & 2 & 0.11 & 0.9 & 0.068 & 0.97 & 0.955 \\
\hline & 3 & 0.06 & 0.96 & 0.02 & 0.99 & 0.98 \\
\hline & 4 & 0.036 & 0.996 & 0.004 & 0.994 & 0.983 \\
\hline \multirow{6}{*}{$\begin{array}{l}\text { TAM-N value } \\
(\mathrm{mg} / 100 \mathrm{~g})\end{array}$} & 5 & 0.004 & 1 & 0.006 & 1 & 1 \\
\hline & 1 & 0.791 & 0.791 & 0.922 & 0.922 & 0.906 \\
\hline & 2 & 0.057 & 0.848 & 0.07 & 0.992 & 0.988 \\
\hline & 3 & 0.121 & 0.968 & 0.001 & 0.993 & 0.985 \\
\hline & 4 & 0.016 & 0.985 & 0.001 & 0.994 & 0.982 \\
\hline & 5 & 0.015 & 1 & 0.001 & 0.994 & 0.966 \\
\hline
\end{tabular}

Table 6 Regression equations between textural attributes and freshness of dates

\begin{tabular}{lll}
\hline Y values & Regression equation & Fitting coefficient $\boldsymbol{R}^{2}$ \\
\hline TVB-N value & $Y=-1.411 x_{1}+0.102 x_{2}-19.662 x_{3}+0.067 x_{4}-0.026 x_{5}-22.994 x_{6}+34.164$ & $R^{2}=0.9240$ \\
TBA value & $Y=0.017 x_{1}+0.000 x_{2}+0.259 x_{3}+0.002 x_{4}-0.001 x_{5}+0.215 x_{6}-0.115$ & $R^{2}=0.8010$ \\
POV value & $Y=0.086 x_{1}-0.005 x_{2}+0.518 x_{3}+0.008 x_{4}-0.002 x_{5}+0.339 x_{6}+0.423$ & \\
& $Y=0.010 x_{1}+0.000 x_{2}-0.577 x_{3}+0.003 x_{4}-0.001 x_{5}+0.561 x_{6}+0.701$ & $R^{2}=0.8820$ \\
TAM-N value & & $R^{2}=0.9060$
\end{tabular}




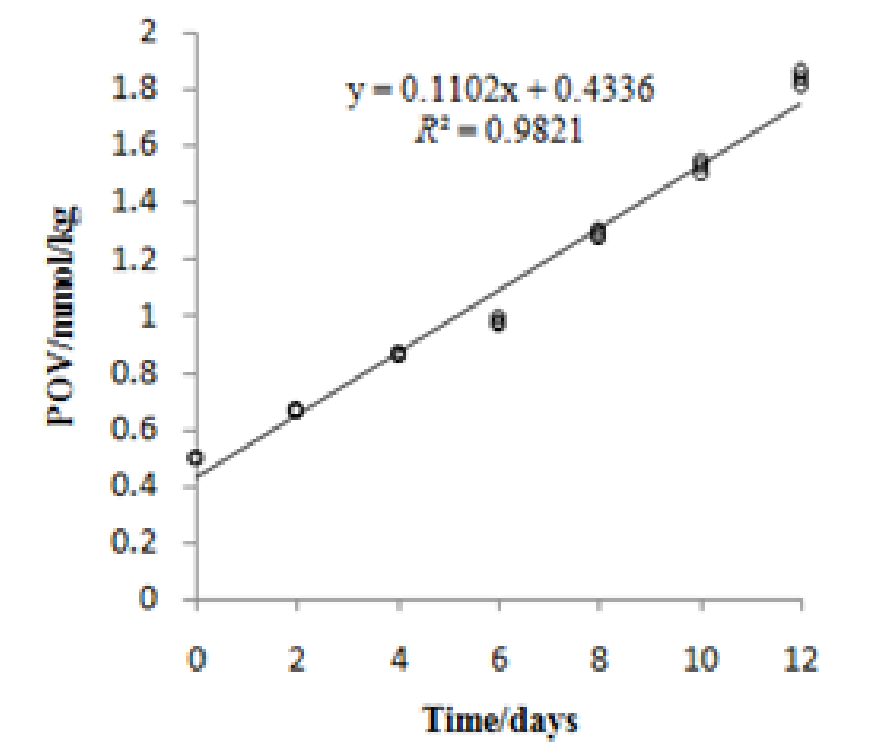

Figure $3 \mathrm{POV}$ value of yak meat during storage.

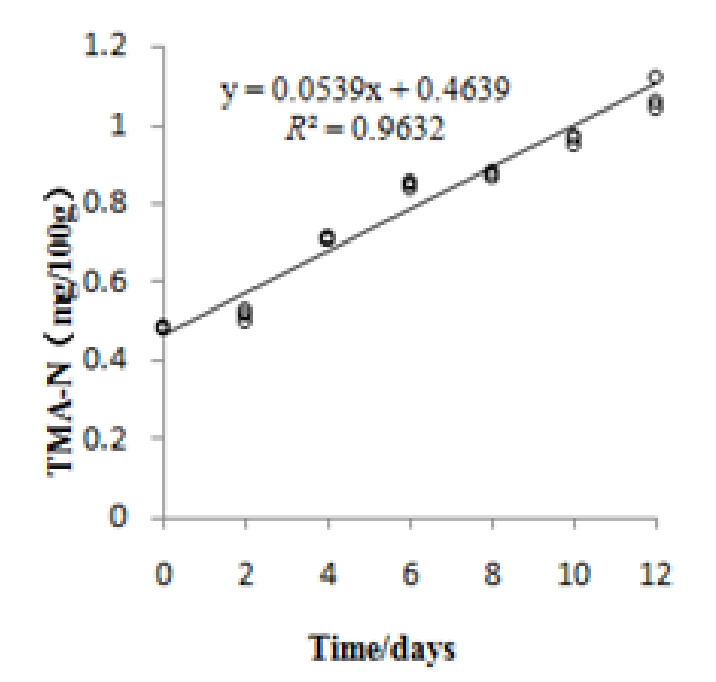

Figure 4 TMA-N value of yak meat during storage.

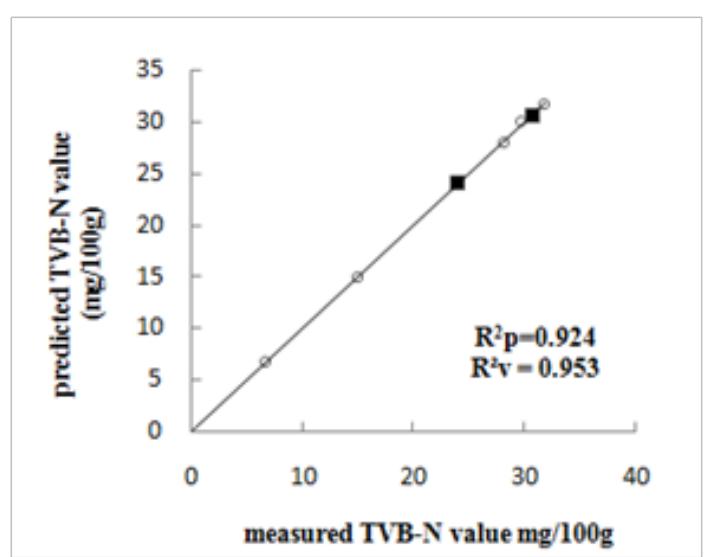

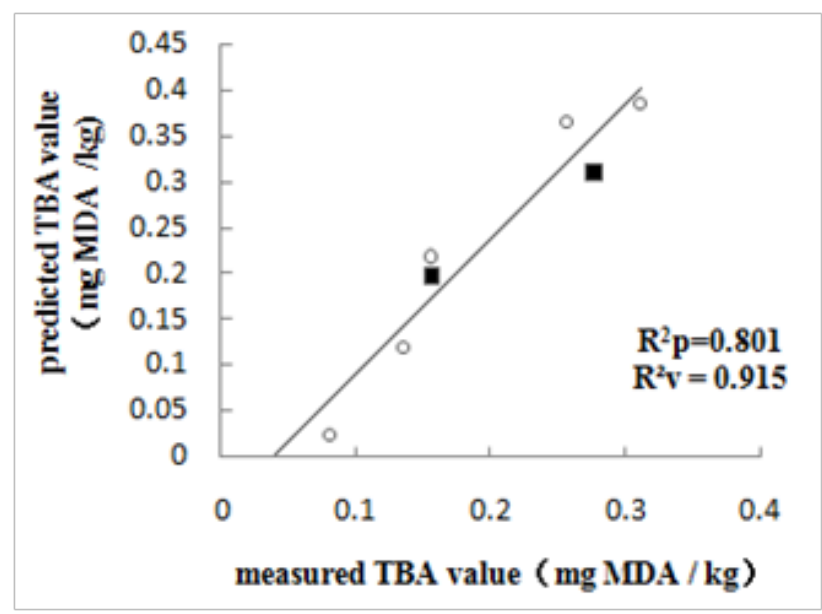

Figure 6 Predicted and measured TBA values for the PLSR.

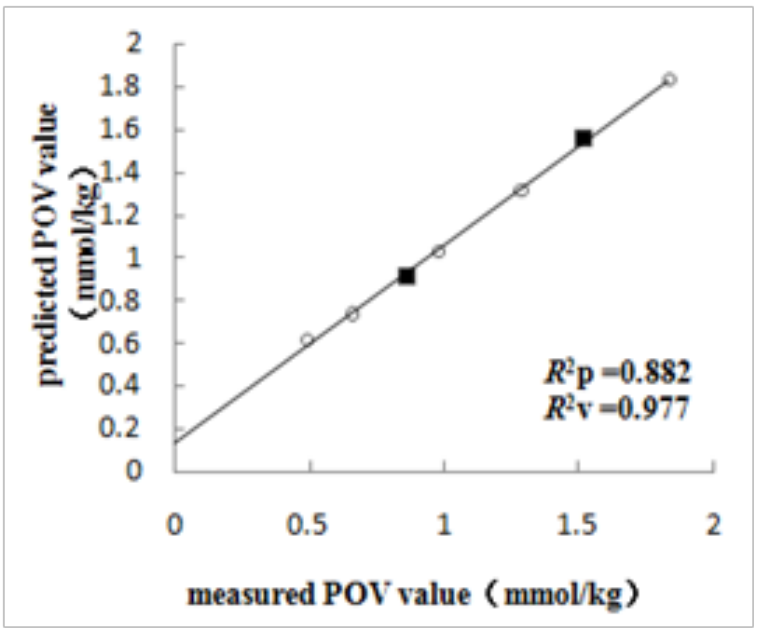

Figure 7 Predicted and measured POV values for the PLSR.

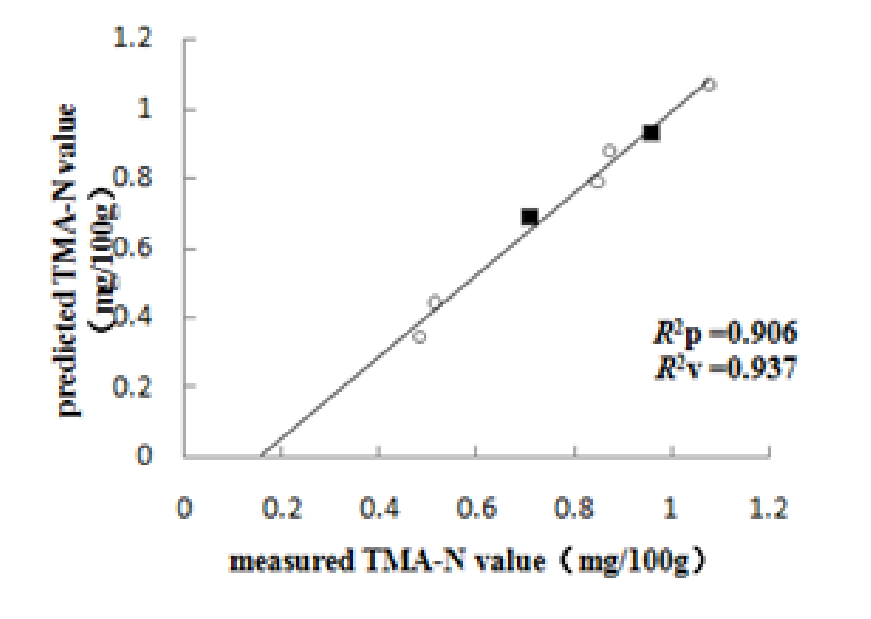

Figure 8 Predicted and measured TMA-N values for the PLSR.

Figure 5 Predicted and measured TVB-N values for the PLSR. 


\section{Conclusion}

The muscle long is simus dorsi of yak meat as the experimental material in this study, and conducted to determine the freshness and the texture profile analysis (TPA), using the PLSR establish the regression equation between freshness and the texture profile analysis (TPA), the values of R2p were greater than 0.80 , From the statistics, it was more than $80 \%$ for evaluation of yak meat freshness quality using TPA parameters, and the value of $R^{2}{ }_{v}$ were greater than 0.90.The relative errors between predicted value and measured value were less than $10 \%$, the value of $R^{2}$ were greater than 0.80 , and the value of the relative errors were less than $5 \%$. Therefore, the regression model established based upon the PLSR using the TPA parameters predicted the freshness, it can be acquired the data close to measured value, which was more powerful in predicting the freshness of yak meat.

\section{Acknowledgements}

This work was supported by the Organization Department of Gansu Province "Long Yuan innovative talents" Program, the Qinghai-Tibet Plateau organic livestock production technology and industrial model of characteristics (201203009).

\section{Conflict of interest}

The author declares no conflict of interest.

\section{References}

1. Wen WT, Luo XL, Xia BX, et al. Post-mortem oxidative stability of three yak (Bos grunniens) muscles as influenced by animal age. Meat Sci. 2015;105:121-125.

2. Huang QP, Chen QS, Li HH, et al. Non-destructively sensing pork's freshness indicator using near infrared multispectral imaging technique. Journal of Food Engineering. 2015;154:69-75.

3. Sinelli N, Limbo S, Torri L, et al. Evaluation of freshness decay of minced beef stored in high-oxygen modified atmosphere packaged at different temperatures using NIR and MIR spectroscopy. Meat Sci. 2010;86(3):748752 .

4. Alomar D, Gallo C, Castaneda M, et al. Chemical and discriminant analysis of bovine meat by near infrared reflectance spectroscopy (NIRS). Meat Sci. 2003;63(4):441-450.

5. Wang XW, Zhao MC, Ju RH, et al. Visualizing quantitatively the freshness of intact fresh pork using acousto-optical tunable filter-based visible/ near-infrared spectral imagery. Computers and Electronics in Agriculture. 2013;99:41-53.

6. Li HH, Chen QS, Zhao JW, et al. Nondestructive detection of total volatile basic nitrogen (TVB-N) content in pork meat by integrating hyperspectral imaging and colorimetric sensor combined with a nonlinear data fusion. LWT - Food Science and Technology. 2015;63(1):268-274

7. Xiong $\mathrm{ZJ}$, Sun $\mathrm{DW}, \mathrm{Pu} \mathrm{HB}$, et al. Non-destructive prediction of thiobarbituricacid reactive substances (TBARS) value for freshness evaluation of chicken meat using hyperspectral imaging. Food Chem. 2015; 179:175-181.

8. Dai Q, Cheng JH, Sun DW, et al. Potential of visible/near-infrared hyperspectral imaging for rapid detection of freshness in unfrozen and frozen prawns. Journal of Food Engineering. 2015;149:97-104.

9. Chen L, Wang JY, Li XW. Regression analysis of instrumental texture characteristics and sensory characteristics of pork. Nongye Gongcheng Xuebao/transactions of the Chinese Society of Agricultural Engineering. 2010;26(6):357-362.
10. Rahman MS, Al-Farsi SA. Instrumental texture profile analysis (TPA) of date flesh as a function of moisture content. Journal of Food Engineering. 2005;66(4):505-511.

11. Sun W, Li H, Wang H, et al. Sensitivity enhancement of $\mathrm{pH}$ indicator and its application in the evaluation of fish freshness. Talanta. 2015;143:127131 .

12. Cheng JH, Sun DW, Zeng XA, et al. Non-destructive and rapid determination of TVB-N content for freshness evaluation of grass carp (Ctenopharyngodon idella) by hyperspectral imaging. Innovative Food Science \& Emerging Technologies. 2014;21:179-187.

13. Siu GM, Draper HH. A Survey of the malonaldehyde content of retail meats and fish. Journal of Food Science. 1978;43(4):1147-1149.

14. Jung GW, Kang HM, Chun BS. Characterization of wheat bran oil obtained by supercritical carbon dioxide and hexane extraction. Journal of Industrial and Engineering Chemistry. 2012;18(1):360-363.

15. Pena-Pereira F, Lavilla I, Bendicho C. Colorimetric assay for determination of trimethylamine-nitrogen (TMA-N) in fish by combining headspacesingle-drop microextraction and microvolume UV-vis spectrophotometry. Food Chemistry. 2010;119(1):402-407.

16. Herrero AM, de la Hoz L, Ordóñez JA, et al. Tensile properties of cooked meat sausages and their correlation with texture profile analysis (TPA) parameters and physico-chemical characteristics. Meat Sci. 2008;80(3):690-696

17. Paula AM, Conti-Silva AC. Texture profile and correlation between sensory and instrumental analyses on extruded snacks. Journal of Food Engineering. 2014;121:9-14.

18. Durgadevi M, Shetty PH. Effect of ingredients on texture profile of fermented food, Idli. APCBEE Procedia. 2012;2:190-198.

19. Cai JR, Chen QS, Wan XM, et al. Determination of total volatile basic nitrogen (TVB-N) content and Warner-Bratzler shear force (WBSF) in pork using Fourier transform near infrared (FT-NIR) spectroscopy. Food Chemistry. 2011;126(3):1354-1360.

20. Li TT, Li JR, Hu WZ, et al. Shelf-life extension of crucian carp (Carassius auratus) using natural preservatives during chilled storage. Food Chemistry. 2012;135(1):140-145.

21. Fan WJ, Zhang YK, Chen YC, et al. TBARS predictive models of pork sausages stored at different temperatures. Meat Sci. 2014;96(1):1-4.

22. Wang JH, Liu DM, Zheng AN, et al. Preliminary purification and distribution of lipoxygenase in grass carp. Advanced Materials Research. 2012;550-553:1468-1472.

23. Debevere J, Boskou G. Effect of modified atmosphere packaging on the TVB/TMA-producing microflora of cod fillets. Int $J$ Food Microbiol. 1996;31(1-3):221-229.

24. Caine WR, Aalhus JL, Best DR, et al. Relationship of texture profile analysis and Warner-Bratzler shear force with sensory characteristics of beef rib steaks. Meat Sci. 2003;64(4):333-339.

25. Ruiz de Huidobro F, Miguel E, Blázquez B, et al. A comparison between two methods (Warner-Bratzler and texture profile analysis) for testing either raw meat or cooked meat. Meat Science. 2005;69(3):527-536.

26. Dolores Romero De Ávila M, Isabel Cambero M, Ordóñez JA, et al. Rheological behaviour of commercial cooked meat products evaluated by tensile test and texture profile analysis (TPA). Meat Science. 2014;98(2):310-315.

27. Ruiz De Huidobro F, Miguel E, Onega E, et al. Changes in meat quality characteristics of bovine meat during the first 6 days post mortem. Meat Sci. 2003;65(4):1439-1446. 
28. Yilmaz MT, Karaman S, Dogan M, et al. Characterization of $\mathrm{O} / \mathrm{W}$ model system meat emulsions using shear creep and creep recovery tests based on mechanical simulation models and their correlation with texture profile analysis (TPA) parameters. Journal of Food Engineering. 2012;108(2):327-336.

29. Saldaña E, Behrens JH, Serrano JS, et al. Microstructure, texture profile and descriptive analysis of texture for traditional and light mortadella. Food Structure. 2015;6:13-20.
30. Font-i-Furnols M, Brun A, Tous N, et al.Use of linear regression and partial least square regression to predict intramuscular fat of pig loin computed tomography images. Chemometrics and Intelligent Laboratory Systems. 2013;122:58-64.

31. Madigan T, Kiermeier A, Carragher J, et al. The use of rapid instrumental methods to assess freshness of half shell Pacific oysters, Crassostrea gigas: A feasibility study. Innovative Food Science \& Emerging Technologies. 2013;19:204-209. 